\title{
Perceptions of emergency medicine residents and fellows regarding competence, adverse events and reporting to supervisors: a national survey
}

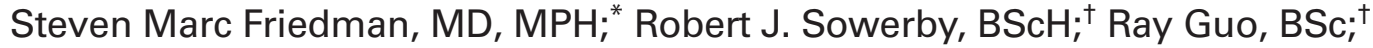 \\ Glen Bandiera, MD, MEd ${ }^{\ddagger}$
}

\section{ABSTRACT}

Objective: We sought to characterize the perceptions of emergency medicine (EM) residents and fellows of their clinical and procedural competence, as well as their attitudes, practices and perceived barriers to reporting these perceptions to their supervisors.

Methods: A Web-based survey was distributed to residents and fellows, via their residency directors, in all Canadian EM residency programs outside of Quebec.

Results: Of 220 residents and fellows contacted in 9 of $10 \mathrm{EM}$ programs of the Royal College of Physicians and Surgeons of Canada and 12 of 13 EM programs of The College of Family Physicians of Canada, 82 (37.3\%) completed all or part of the survey. Response rates varied slightly by question; 25 of 82 respondents (30.5\% [95\% confidence interval (CI) 19.9\%-41.1\%]) agreed with the statement, "I sometimes feel unsafe or unqualified with undertaking unsupervised responsibilities or procedures, but I do not report this to my senior physician" and 32 of 81 (39.5\% [95\% Cl 28.2\%-50.8\%]) had felt this within the past 6 months. Moreover, 34 of 82 (41.5\% [95\% Cl 30.2\%$52.7 \%]$ ) reported their lack of competence to a supervisor half the time or less. Trainees reported worry about loss of trust, autonomy or respect $(38 / 80,47.5 \%$ [95\% Cl 35.9\%-59.1\%]) or reputation $(32 / 80,40.0 \%$ [95\% $\mathrm{Cl} 28.6 \%-51.4 \%])$. Nights on-call (30/79, 38\% [95\% Cl 26.6\%-49.3\%]), admission decisions (13/79, 16.5\% [7.6\%-25.3\%]) and central line insertion (13/79, $16.5 \%$ [95\% Cl $7.6 \%-25.3 \%]$ ]) were reported to be frequently undertaken despite not feeling competent. Suggestions to improve reporting included encouragement to report without penalty $(41 / 82,50.0 \%$ [95\% Cl 38.6\%-61.4\%]) and a less judgmental environment (32/82, 39.0\% [95\% Cl 27.9\%-50.2\%]).

Conclusion: Emergency medicine trainees report that they frequently do not feel competent when undertaking responsi- bilities without supervision. Barriers to reporting these feelings or reporting adverse events appear to relate to social pressures and authority gradients. Modifications to the training culture are encouraged to improve patient safety.

Keywords: postgraduate education, safety, error, reporting, emergency

\section{RÉSUMÉ}

Objectif : Nous avons cherché à caractériser, d'une part, les perceptions des résidents et moniteurs cliniques (fellows) en médecine d'urgence concernant leurs compétences cliniques et procédurales et, d'autre part, leurs attitudes ainsi que leurs pratiques relatives au signalement de ces perceptions à leurs superviseurs et les obstacles qu'ils perçoivent à ce signalement. Méthodes : Nous avons distribué un sondage en ligne aux résidents et aux moniteurs, par le biais de leurs directeurs de résidence, dans tous les programmes canadiens de résidence en médecine d'urgence hors Québec.

Résultats : Parmi les 220 résidents et moniteurs contactés de 9 des 10 programmes en médecine d'urgence du Collège royal des médecins et chirurgiens du Canada et 12 des 13 programmes de médecine d'urgence du Collège des médecins de famille du Canada, 82 (37,3\%) ont rempli le questionnaire en partie ou en totalité. Les taux de réponse variaient légèrement d'une question à l'autre; 25 des 82 répondants (30,5\% [intervalle de confiance (IC) à $95 \%$, de 19,9 à 41,1\%]) étaient d'accord avec l'énoncé « Je considère que parfois, il n'est pas sécuritaire ou que je n'ai pas les qualifications requises pour assumer une responsabilité ou réaliser une procédure sans supervision, mais je ne le mentionne pas au médecin principal ", et 32 des 81 répondants (39,5\% [IC à $95 \%$, de 28,2 à 50,8 \%]) s'étaient ainsi sentis au cours des 6 derniers mois. En outre, 34 des

From the *Faculty of Medicine, Dalla Lana School of Public Health, the †Faculty of Medicine and the $¥$ Division of Emergency Medicine, Department of Medicine, University of Toronto, Toronto, Ont.

This paper was presented as a poster at the Annual Scientific Meeting of the Canadian Association of Emergency Physicians in Calgary, Alta., June 2009, and as an oral presentation at the Fifth Mediterranean Emergency Medicine Conference, Valencia, Spain, September 2009.

Submitted Dec. 2, 2009; Revised Feb. 9, 2010; Accepted Feb. 16, 2010

This article has been peer reviewed. 
82 répondants (41,5\% [IC à $95 \%$, de 30,2 à 52,7\%]) ont signalé leur manque de compétence à un superviseur la moitié du temps ou moins. Les stagiaires ont déclaré être préoccupés par la perte potentielle de confiance, d'autonomie ou de respect $(38 / 80,47,5 \%$ [IC à $95 \%$, de 35,9 à 59,1\%]) ou par l'atteinte à leur réputation $(32 / 80,40,0 \%$ [IC à $95 \%$, de 28,6 à $51,4 \%$ ]). Ils ont signalé qu'ils entreprenaient les actions suivantes même s'ils ne se sentaient pas compétents : garde de nuit (30/79, $38 \%$ [IC à $95 \%$, de 26,6 à 49,3\%]), décisions sur I'admission (13/79, $16,5 \%$ [7,6 à 25,3\%]) et insertion d'un cathéter central (13/79, $16,5 \%$ [IC à $95 \%, 7,6$ à 25,3\%]). Parmi les suggestions pour améliorer le signalement, citons des encouragements à parler à leurs superviseurs à ces sujets sans pénalité $(41 / 82,50,0 \%$ [IC à $95 \%$, de 38,6 à $61,4 \%]$ ) et un environnement où moins de jugements sont portés (32/82, 39,0 \% [IC à $95 \%$, de 27,9 à 50,2 \%]).

Conclusion : Les médecins en formation signalent que souvent, ils ne se sentent pas compétents pour assumer des responsabilités sans supervision. Les obstacles à communiquer ces préoccupations ou à signaler des événements indésirables semblent liés aux pressions sociales et aux chaînes d'autorité. On encourage l'apport de modifications à la culture de formation pour améliorer la sécurité des patients.

\section{INTRODUCTION}

\section{Background}

In Canadian hospitals, $7.5 \%$ of admissions are associated with an adverse event (AE) and a trend exists toward higher numbers of AEs in teaching hospitals. Almost $40 \%$ of AEs have been reported to be preventable. In Canada AEs result in 23750 deaths per year and $\$ 750$ million in expenses., ${ }^{2,3}$ Similar results have been reported in US centres.,5

Studies suggest high rates of AEs involving residents. In a survey of 689 residents, $6.6 \%$ reported being responsible for an $\mathrm{AE}$ in the prior week. ${ }^{6}$ Inadequate experience and knowledge have been cited as important causes of AEs involving residents. ${ }^{7,8}$ Residents and fellows may be predisposed to involvement in AEs because of the nature of their educational experience. ${ }^{9}$ Many aspects of medical learning involve trial and error in a culture that is often characterized by the mantra "See one, do one, teach one." Furthermore, patients in teaching hospitals often have complex illnesses, present late in their illness and require more sophisticated care. ${ }^{10}$ Finally, residents and fellows take on new responsibilities and perform increasingly complex procedures with little or no supervision, and often work long hours, resulting in sleep deprivation. ${ }^{8,9}$ In 2008, the Institute of Medicine recommended new safety measures that included alleviating fatigue and sleep loss among residents, increasing their supervision by senior physicians and improving transfers of care. ${ }^{11}$

\section{Importance}

Reporting of AEs is essential to the identification and improvement of hazardous processes, and offers the addi- tional advantages of emotional relief, enhanced learning, improvement in personal practice and decreased likelihood of legal liability. ${ }^{12,13}$ However, current methods of $\mathrm{AE}$ reporting create barriers and hence poor rates of reporting. Physicians are reluctant to report AEs to a superior, and studies indicate $50 \%-96 \%$ of AEs are unreported. ${ }^{14-16}$ Barriers to reporting include a high workload, time-consuming protocols, lack of feedback, belief that the incident was trivial and fears regarding litigation with resultant career impact. ${ }^{17}, 18$ Physician compliance with other forms of mandatory reporting — such as reporting of communicable disease - is similarly poor. ${ }^{19}$

Residents and fellows may be reluctant to report feeling not competent or "safe" to their supervisor for similar reasons. In a study of 654 internal medicine residents, only $60 \%$ felt prepared to be a member of a cardiac arrest team and $55 \%$ suspected that they had made errors during cardiac arrests. ${ }^{20}$ Self-awareness and responsibility for safe care are tied directly to competencies within common residency training paradigms, such as the "Manager" and "Professional" roles within the CanMEDS framework. ${ }^{10,21}$ The moral and professional duty of a trainee to report feeling not competent conflicts with fears of recrimination or negative professional impact if such feelings are reported. Authority gradients can act as barriers to reporting when senior physicians involved in the reporting structure have influence in the career advancement of the trainee. ${ }^{22,23}$

\section{Goals of this investigation}

The purpose of this study was to characterize the perceptions of emergency medicine (EM) residents and fellows of their clinical and procedural competence, as well as their attitudes, practices and perceived barriers to reporting these perceptions to their supervisors. 


\section{METHODS}

\section{Study design}

A survey instrument was designed using Survey Monkey. Quantitative data were collected using a 5-point agreement scale (ranging from strongly disagree to strongly agree) and a 5-point frequency scale (ranging from rarely to almost always) as appropriate. Qualitative data was captured as free text. The survey was piloted by an EM residency program director and 4 EM residents for face and content validity, and revised accordingly.

An $\mathrm{AE}$ was defined as "a complication, injury, or harm to a patient resulting from medical management (not from the patient's underlying condition or disease).”

\section{Setting and participants}

An anonymous Web-based survey was carried out from January through March 2008 of all Canadian EM residents outside of Quebec in the EM programs of the Royal College of Physicians and Surgeons of Canada and The College of Family Physicians of Canada. The program directors were contacted by email and/or telephone and asked to forward an email to all EM residents and fellows. The email contained an overview of the study and electronic link to the study website; the website contained an introductory letter to the study, a detailed consent form and the survey instrument.

\section{Data collection and processing}

Using a modified Dillman approach, each participating program director was sent 3 weekly reminder emails to reforward the invitation. ${ }^{24}$ Participating program directors provided the investigators the number of trainees to whom they sent the initial invitation and follow-up reminders, but not their identity. Data collection was structured to preserve anonymity, and participants were asked to refrain from submitting any identifying information for themselves, their patients or their institutions. Participants were instructed to complete the survey only once. Program directors were contacted after a 4-week period and at the end of the study period to confirm their compliance with the protocol.

\section{Data analysis}

Data analysis was performed using Microsoft Excel 2003. Proportions with $95 \%$ confidence intervals (CIs) were generated for descriptive statistics. We used $t$ tests for continuous variables and $\chi^{2}$ for categorical variables for statistical testing.

The study was approved by the University Health Network Research Ethics Board.

\section{RESULTS}

\section{Response and demographic characteristics}

Nine of 10 FRCP(EM) and 12 of 13 CFPC(EM) program directors participated; one declined to participate, and one could not be reached despite numerous attempts. All participating program directors confirmed that they had forwarded the initial invitation letter and 2 follow-up emails to their trainees. The response rate was $37.3 \% ; 220$ EM trainees were invited and 82 completed all or part of the survey (78 residents and 1 fellow completed all of the survey and 3 did not complete the demographics section).

\section{Demographics}

Demographic information is provided in Table 1. Of the 79 respondents who completed the demographic section of the survey, 45 (57.0\%) were in an FRCP(EM) program and $34(43.0 \%)$ were in a CCFP(EM) program. The $\mathrm{CCFP}(\mathrm{EM})$ program runs as a single year

Table 1. Demographic characteristics of the study population

\begin{tabular}{|c|c|}
\hline Characteristic & No. (\%) of respondents* \\
\hline \multicolumn{2}{|l|}{$\operatorname{Sex}(n=79)$} \\
\hline Male & $43(54.4)$ \\
\hline Female & $36(45.6)$ \\
\hline Mean (range) age, yr $(n=77 \dagger)$ & $29.5(25-37)$ \\
\hline \multicolumn{2}{|l|}{ Postgraduate year $(n=79)$} \\
\hline 1 & $13(16.5)$ \\
\hline 2 & 7 (8.9) \\
\hline 3 & $41(51.9)$ \\
\hline 4 & $11(13.9)$ \\
\hline 5 & 6 (7.6) \\
\hline$\geq 6$ & 1 (1.3) \\
\hline \multicolumn{2}{|l|}{ Medical training $(n=79)$} \\
\hline Canada & 70 (88.6) \\
\hline United States & 1 (1.3) \\
\hline Elsewhere & $8(10.1)$ \\
\hline \multicolumn{2}{|c|}{ Language spoken at home $(n=78 \dagger)$} \\
\hline English & $70(89.7)$ \\
\hline French & 1 (1.3) \\
\hline Other & $7 \quad(9.0)$ \\
\hline
\end{tabular}

*Unless otherwise indicated.

tSome respondents did not complete the demographics section of the survey. 
after 2 years of training in family medicine, thus all CCFP(EM) participants were in their third postgraduate year, and represented $82.9 \%$ of the 41 respondents in their third postgraduate year.

\section{Perceptions of personal competence}

Trainees were asked, "When was the last time you performed a procedure or undertook a clinical responsibility with minimal or no supervision which you did not feel confident performing independently?" Twelve trainees (14.8\% [95\% CI 6.5\%-23.2\%]) had experienced this in the past month, and 32 (39.5\% [95\% CI $28.2 \%-50.8 \%])$ indicated that this had occurred within the past 6 months.

Table 2 provides information on procedures or responsibilities performed unsupervised despite trainees not feeling competent or "safe" to perform these independently. Nights on-call, admission decisions and invasive procedures were most frequently undertaken despite trainees not feeling competent.

\section{Reporting}

Table 3 provides information on reporting. Almost onethird of the study participants $(25 / 82,30.5 \%$ [95\% CI $19.9 \%-41.1 \%]$ ) agreed with the statement, "I sometimes feel unsafe or unqualified when undertaking certain unsupervised responsibilities or procedures that I am expected to do, but I do not report this to my senior physician." Moreover, 34 of 82 (41.5\% [95\% CI 30.2\%$52.7 \%]$ ) reported their lack of competence to a supervisor half the time or less.

\section{Barriers to reporting and suggestions for improvement}

The primary causes for trainees not reporting feeling unsafe or not competent, as selected from a list or

\begin{tabular}{|c|c|c|c|c|}
\hline Response option & $\begin{array}{l}\text { Response, } \\
\%\end{array}$ & $\begin{array}{l}\text { Response } \\
\text { count* }\end{array}$ & SE, \% & $95 \% \mathrm{Cl}$ \\
\hline Providing on-call care overnight & 38.0 & 30 & 5.5 & $26.6 \%-49.3 \%$ \\
\hline Complex wound care & 27.8 & 22 & 5.0 & $17.3 \%-38.4 \%$ \\
\hline This situation has not occurred & 25.3 & 20 & 4.9 & $15.1 \%-35.5 \%$ \\
\hline Inserting a central line & 16.5 & 13 & 4.2 & $7.6 \%-25.3 \%$ \\
\hline $\begin{array}{l}\text { Deciding whether to discharge or admit a } \\
\text { patient }\end{array}$ & 16.5 & 13 & 4.2 & $7.6 \%-25.3 \%$ \\
\hline Supervising a resuscitation or cardiac arrest & 11.4 & 9 & 3.6 & $3.8 \%-19.0 \%$ \\
\hline Breaking bad news & 10.1 & 8 & 3.4 & $2.8 \%-17.4 \%$ \\
\hline Endotracheal intubation & 8.9 & 7 & 3.2 & $2.0 \%-15.8 \%$ \\
\hline Lumbar puncture & 3.8 & 3 & 2.2 & $0.0 \%-8.6 \%$ \\
\hline Obtaining an arterial blood gas & 2.5 & 2 & 1.8 & $0.0 \%-6.6 \%$ \\
\hline Cardioversion/defibrillation & 1.3 & 1 & 1.3 & $0.0 \%-4.4 \%$ \\
\hline Other & 12.7 & 10 & 3.7 & $4.7 \%-20.6 \%$ \\
\hline
\end{tabular}

$\mathrm{Cl}=$ confidence interval; $\mathrm{SE}=$ standard error.

*This question was answered by 79 respondents and skipped by 3 respondents.

Table 3. Responses to the question, "When you feel unsafe or not competent to undertake a clinical responsibility independently, how often do you report this to your supervising physician (resident or staff)?"

\begin{tabular}{lcccc}
\hline Response option & $\begin{array}{c}\text { Response, } \\
\%\end{array}$ & $\begin{array}{c}\text { Response } \\
\text { count* }\end{array}$ & SE, \% & $95 \% \mathrm{Cl}$ \\
\hline Rarely (0\%-20\% of the time) & 9.8 & 8 & 3.3 & $2.7 \%-16.8 \%$ \\
Infrequently (21\%-40\% of the time) & 9.8 & 8 & 3.3 & $2.7 \%-16.8 \%$ \\
About half the time (41\%-60\% of the time) & 22.0 & 18 & 4.6 & $12.4 \%-31.5 \%$ \\
Very frequently (61\%-80\% of the time) & 17.1 & 14 & 4.2 & $8.3 \%-25.8 \%$ \\
Almost always (81\%-100\% of the time) & 41.5 & 34 & 5.4 & $30.2 \%-52.7 \%$ \\
\hline Cl = confidence interval; SE = standard error. & & & \\
*This question was answered by 82 respondents and skipped by 0 respondents. & & &
\end{tabular}


entered as free text, were being worried about loss of trust, autonomy or respect by the supervising physician (38/80, 47.5\% [95\% CI 35.9\%-59.1\%]), loss of reputation with the supervising physician (32/80, 40.0\% [95\% CI $28.6 \%-51.4 \%]$ ), a negative impact on evaluation (17/89, 21.3\% [95\% CI 11.7\%-30.8\%]), being too busy (23/80, 28.9\% [95\% CI 18.2\%-39.3\%]) and not wanting to bother the supervising physician $(21 / 80,26.3 \%$ [95\% CI $16.0 \%-36.5 \%])$. Only 19 of 80 respondents (23.8\% [95\% CI $13.8 \%-33.7 \%]$ ) endorsed the statement, "This scenario never occurs."

Table 4 outlines suggestions of trainees for improving reporting. These suggestions most frequently included encouragement to report without penalty and a less judgmental environment.

\section{Perceptions regarding AEs and reporting}

Almost two-thirds of the study participants (52/82, $63.4 \%$ ) indicated that they had, in the past year, felt responsible for an $\mathrm{AE}$ after providing medical care or performing a procedure they had felt competent to perform independently, with more than one-third (28/82, $34.1 \%$ [95\% CI $23.3 \%-45.0 \%]$ ) reporting that this had occurred within the past 6 months.

Table 5 provides information on the consequences of the most serious AEs trainees felt responsible for. Most reported that the consequences were minor, although significant outcomes - including death — were described.

When asked to describe the most significant medical $\mathrm{AE}$ for which they felt some responsibility, trainees

\begin{tabular}{|c|c|c|c|c|}
\hline Response option & $\begin{array}{l}\text { Response, } \\
\%\end{array}$ & $\begin{array}{c}\text { Response } \\
\text { count† }\end{array}$ & $\mathrm{SE}, \%$ & $95 \% \mathrm{Cl}$ \\
\hline Encouragement to report without penalty & 50.0 & 41 & 5.5 & $38.6 \%-61.4 \%$ \\
\hline A less judgmental environment & 39.0 & 32 & 5.4 & $27.9 \%-50.2 \%$ \\
\hline $\begin{array}{l}\text { Periodic anonymous surveys of trainees } \\
\text { regarding perceived competence and safety }\end{array}$ & 24.4 & 20 & 4.7 & $14.5 \%-34.3 \%$ \\
\hline There is no need to improve the system & 19.5 & 16 & 4.4 & $10.3 \%-28.7 \%$ \\
\hline $\begin{array}{l}\text { Specific education in roots of medical error } \\
\text { and/or communication }\end{array}$ & 18.3 & 15 & 4.3 & $9.3 \%-27.3 \%$ \\
\hline Anonymous reporting & 14.6 & 12 & 3.9 & $6.4 \%-22.9 \%$ \\
\hline Other & 4.9 & 4 & 2.4 & $0.0 \%-10.2 \%$ \\
\hline
\end{tabular}

\begin{tabular}{|c|c|c|c|c|}
\hline Response option & $\begin{array}{l}\text { Response, } \\
\%\end{array}$ & $\begin{array}{c}\text { Response } \\
\text { count } \dagger\end{array}$ & SE, \% & $95 \% \mathrm{Cl}$ \\
\hline $\begin{array}{l}\text { I cannot recall responsibility for an adverse } \\
\text { event/unknown/none apparent }\end{array}$ & 58.8 & 47 & 5.5 & $47.3 \%-70.2 \%$ \\
\hline Delayed treatment & 16.3 & 13 & 4.1 & $7.5 \%-25.0 \%$ \\
\hline Pain & 13.8 & 11 & 3.9 & $5.6 \%-21.9 \%$ \\
\hline Impairment with expected recovery & 13.8 & 11 & 3.9 & $5.6 \%-21.9 \%$ \\
\hline Increased hospital stay & 12.5 & 10 & 3.7 & $4.6 \%-20.4 \%$ \\
\hline Delayed diagnosis & 12.5 & 10 & 3.7 & $4.6 \%-20.4 \%$ \\
\hline $\begin{array}{l}\text { Permanent impairment with little disability } \\
\text { (e.g., scar) }\end{array}$ & 5.0 & 4 & 2.4 & $0.0 \%-10.4 \%$ \\
\hline Death & 3.8 & 3 & 2.1 & $0.0 \%-8.5 \%$ \\
\hline $\begin{array}{l}\text { Permanent impairment with great disability } \\
\text { (e.g., amputation, myocardial infarction) }\end{array}$ & 2.5 & 2 & 1.7 & $0.0 \%-6.5 \%$ \\
\hline Other & 5.0 & 4 & 2.4 & $0.0 \%-10.4 \%$ \\
\hline
\end{tabular}


most frequently described complications related to procedures - primarily insertions of chest tubes, central lines and paracentesis $(22 / 55,40.0 \%)$, errors in diagnosis or treatment $(15 / 55,27.3 \%)$ and errors related to management of medication $(8 / 55,14.5 \%)$.

Trainees described heterogeneous rates of reporting of AEs. The majority stated that they had reported the most serious AE for which they felt responsible to their attending physician $(40 / 63,63.5 \%$ [95\% CI 50.8\%$76.2 \%]$ and/or to their senior resident $(22 / 63,34.9 \%$ [95\% CI $22.4 \%-47.5 \%])$. Less than one-quarter $(15 / 63,23.8 \%$ [95\% CI $12.5 \%-35.1 \%])$ reported the event to the patient or to the patient's family. Only 6 of $63(9.5 \%)$ reported the event through their hospital reporting system. Of note, 12 of 63 trainees (19\% [95\% CI $8.6 \%-29.5 \%$ ]) did not report the worst AE for which they felt responsible to either their senior resident or their attending physician. The response rate to this question was $76.8 \%(63 / 82)$.

\section{Barriers to reporting AEs}

Table 6 provides information on barriers to reporting. The most frequently identified barrier to reporting AEs was worry about loss of trust, autonomy or respect from the supervising physician. Social barriers related to authority gradients were more frequently described than those related to administrative or systems functions such as not knowing what events to report or being too busy and forgetful. Occasional respondents identified fear of appearing incompetent (1 respondent, $1.3 \%$ ) and worry about public humiliation and shame (1 respondent, $1.3 \%)$, as exemplified by the statement, "I also find many nurses are publicly very derogatory towards residents if an error/poor judgment occurs on the service."

\section{DISCUSSION}

\section{Perceptions of not being competent or safe}

Approximately $40 \%$ of EM residents and trainees had, within the 6 months before completing the survey, felt not competent performing their duties but did not report this to their supervisor. Trainees frequently reported feeling unsafe when on-call overnight, deciding to admit or discharge patients and undertaking invasive procedures. These responses - coupled with a frequent reluctance to bring such feelings to the attention of supervising physicians - are patient safety concerns, as trainees are front-line providers integral in providing off-hour care in teaching hospitals.

Several studies have found increased morbidity and mortality on the weekends in teaching hospitals, when trainees are less closely supervised..$^{25,26}$ This may relate to procedural and clinical competence. In a Canadian survey of internal medicine residents, $44.3 \%$ indicated having felt overwhelmed leading resuscitations in cardiac arrest, and $55.3 \%$ worried that they had made

\begin{tabular}{|c|c|c|c|c|}
\hline Response option & $\begin{array}{l}\text { Response, } \\
\%\end{array}$ & $\begin{array}{l}\text { Response } \\
\text { count }\end{array}$ & SE, \% & $95 \% \mathrm{Cl}$ \\
\hline I report all events & 45.0 & 36 & 5.6 & $33.5 \%-56.5 \%$ \\
\hline $\begin{array}{l}\text { Worried about loss of trust, autonomy or } \\
\text { respect by your senior }\end{array}$ & 35.0 & 28 & 5.3 & $23.9 \%-46.1 \%$ \\
\hline Don't know which events to report & 18.8 & 15 & 4.4 & $9.6 \%-27.9 \%$ \\
\hline Too busy and/or forget to report & 15.0 & 12 & 4.0 & $6.6 \%-23.4 \%$ \\
\hline Residents are unfairly blamed for errors & 12.5 & 10 & 3.7 & $4.6 \%-20.4 \%$ \\
\hline It may negatively impact my evaluation & 12.5 & 10 & 3.7 & $4.6 \%-20.4 \%$ \\
\hline Competitive environment & 8.8 & 7 & 3.2 & $1.9 \%-15.6 \%$ \\
\hline Worried about impacts on career & 5.0 & 4 & 2.4 & $0.0 \%-10.4 \%$ \\
\hline Worried about litigation (a lawsuit) & 3.8 & 3 & 2.1 & $0.0 \%-8.5 \%$ \\
\hline Lengthy reporting procedure & 2.5 & 2 & 1.7 & $0.0 \%-6.5 \%$ \\
\hline My senior does not want me to report & 2.5 & 2 & 1.7 & $0.0 \%-6.5 \%$ \\
\hline Reporting increases my workload & 1.3 & 1 & 1.2 & $0.0 \%-4.3 \%$ \\
\hline Other (please describe) & 7.5 & 6 & 2.9 & $1.1 \%-13.9 \%$ \\
\hline None & 3.8 & 3 & 2.1 & $0.0 \%-8.5 \%$ \\
\hline
\end{tabular}


errors during such events. ${ }^{20}$ In a survey of Canadian pediatric EM fellows, the median self-estimated success rate for internal jugular and subclavian central line insertion was $50 \%$ or less. ${ }^{27}$

Although it could be argued that feeling unsafe is a normal part of the learning process and may not reflect actual abilities, resident experiences with AEs suggest that their perceptions may often be valid. Singh and colleagues $^{28}$ analyzed malpractice claims in which trainees were judged to have played an important role in harmful errors. Teamwork breakdowns — primarily a lack of supervision and hand-off problems - were contributing factors in $70 \%$ of cases, and lack of technical competence were contributing factors in $58 \%$ of cases.

\section{Reporting practices}

In our study, rates of residents failing to report AEs were comparable to rates of residents failing to report feelings of not being competent. Farnan and colleagues ${ }^{29}$ interviewed residents about important clinical decisions made while on call and about their experiences with clinical uncertainty. They found reluctance among residents surveyed to seek advice from staff that often prompted initial reliance on peers in a manner that, on occasion, resulted in delays in indicated care and even patient harm. Similar low rates of resident reporting of AEs have been described in other studies. ${ }^{6,7,12}$

\section{Improving safety culture in the training environment}

Residents and fellows endorsed a training environment that is less punitive and places more emphasis on reporting. Medical education appears to be evloving in that direction. Whereas Leape ${ }^{30}$ remarked in 1998 that "physicians are socialized in medical schools to strive for errorfree practice," Cuschieri ${ }^{31}$ noted in 2006 that efforts across multiple health delivery systems were being undertaken to move from the defensive "blame and shame culture" to an open and transparent health care delivery system.

Proposed changes to improve reporting are described in the literature. Curricula for teaching patient safety to medical students and trainees have been developed, focusing on awareness of error, cognitive sources of error and cognitive forcing strategies to mitigate error. ${ }^{32}$ Thompson and colleagues ${ }^{33}$ described a multidisciplinary system-based curriculum of safety and AE reporting introduced for first-year medical students that showed that perceptions of patient harm and the role physicians play in patient safety can be changed.
Error-reducing strategies have been described for practice at the residency level. Gutierrez and colleagues ${ }^{34}$ note that physicians may be more inclined to report near misses - as they occur more frequently and with fewer consequences to the patient - and advocate integrating the reporting of near misses into the shift signout routine. These authors also advocate analyzing reported events and incorporating reporting of errors into medical school curricula as early as first year. The addition of an online $\log$ of error reporting as part of residents sign-out routine has been described as a timely and convenient process to encourage reporting. ${ }^{35}$ Rodriguez-Paz and colleagues ${ }^{36}$ proposed a new training paradigm that integrates competency-based knowledge and clinical skills with deliberate attitudinal and behavioural changes focused on patient safety in a simulated environment. The Canadian Patient Safety Institute published a safety framework that identified $20 \mathrm{key}$ competencies and 140 enabling competencies for the patient safety education of health care professionals. ${ }^{37}$

Most competency-based frameworks include professionalism and management skills and include principles of patient safety and quality improvement. Deriving specific enabling competencies to describe self-awareness in practice, and designing instruments such as evaluation forms and multisource feedback tools to address these competencies may increase awareness and acceptability. Similarly, modifying trainees' evaluations of teachers to include receptiveness to being contacted and openness to a trainee's declaration of lack of competence may have similar affect. Web-based reporting systems are being trialed in some hospital environments in an effort to increase reporting by all hospital staff, and trainees should be included in these initiatives. Finally, as these issues arise from cultural constructs, systematic change from the top down is a prerequisite for lasting change, and necessitates leaders, teachers and supervisors to act as, and be perceived as, role models. Accordingly, educational leaders must emphasize that supervisors should be receptive to trainees' concerns and respond appropriately and constructively. Further to this, the system must enable leaders to address teachers who do not perform appropriately. Remediation structures, guidelines for supervision and policies regarding intimidation and harassment of residents should be routine in academic centres.

\section{Medicolegal considerations}

One theme arising in this study was that trainees frequently indicated they did not feel it was ultimately 
their responsibility to disclose their perceived lack of competence; rather, it was ultimately the supervisor's job to determine this. This should serve as a cautionary finding for attending physicians, as the medicolegal implications of residents performing assigned duties despite not feeling competent can be shared by trainees and their supervisors.

The Canadian Medical Protective Association serves as the primary medicolegal advisors for $95 \%$ of Canadian physicians. In an article circulated to all its members, the association wrote the following:

In legal actions [that consider the responsibility of supervising physicians], the court generally considers whether the delegation, supervision and support provided by the supervising physician were reasonable in the circumstances. Supervising physicians should therefore consider the following: "Is the task appropriate to delegate to an individual with the trainee's level of training? Does the specific trainee have the required knowledge, skill and experience to perform the task? What degree of supervision is required?" ... Open and supportive communication by the supervisor and readiness to help the trainee will allow the trainee to voice any concerns about a task. The trainee should feel free to clarify instructions, voice concerns and ask the supervisor for help. ${ }^{38}$

The article also addresses the medicolegal responsibility of trainees:

In legal actions, the court generally considers whether the trainee performed at a standard which could reasonably be expected. Trainees and residents should therefore: Recognize the limits of their knowledge. Exercise caution and consider their inexperience. Notify their supervisors of their knowledge, skill and experience with the delegated task. Keep the supervisor informed of their actions. Inform patients of their status as medical trainees. ${ }^{38}$

\section{Limitations}

Several limitations should be considered when interpreting our results. First, our response rate of $37.3 \%$ is low and our resulting sample may not reflect the population of trainees as a whole. We suspect our low response rate arose both because of the sensitive nature of the questions and by our dependence on 2 tiers of participation (recruiting program directors to recruit trainees), as confidentiality precluded release of the email addresses of trainees to the researchers. This said, our response rate is comparable to or better than those seen in similarly designed Web-based studies of medical trainees and in the safety reporting literature. .0,39,40 $^{2}$

Our study population involved Canadian EM trainees outside of Quebec. As a result, our findings are not necessarily generalizable to residents and fellows in
Quebec or in training programs outside of Canada.

Nonresponder bias may have influenced recruitment given the sensitive nature of the study topic, and the experiences of the subgroup that participated may be different from those who chose not to participate in the survey. Moreover, participants may have felt compelled to give socially acceptable responses.

However, even if all nonresponders perceived full competence and experienced AE-free practice, our data would still suggest that the frequency of trainee underreporting to superiors is significant, and a need exists to improve the training culture.

\section{CONCLUSION}

Emergency medicine residents and fellows report that they frequently don't feel competent when undertaking responsibilities without supervision. Barriers to expressing these concerns and reporting AEs relate to social pressures and authority gradients. Modification of the training culture is warranted as part of efforts to improve patient safety. Supervising physicians, as educators, should readily assess the level of experience of trainees and foster a culture that facilitates reporting. A low response rate was a limitation to this study and its findings.

Acknowledgements: The authors thank Tamara Arenovich, who served as a statistical consultant.

Competing interests: None declared.

\section{REFERENCES}

1. Baker GR, Norton PG, Flintoft V, et al. The Canadian Adverse Events Study: the incidence of adverse events among hospital patients in Canada. CMAJ 2004;170:1678-86.

2. Kondro W. Health care dominates run-up to Canadian election. Lancet 2004;363:1877.

3. Canadian Institute for Health Information. Health Care in Canada. Ottawa (ON): The Institute; 2004.

4. Brennan TA, Leape LL, Laird NM, et al. Incidence of adverse events and negligence in hospitalized patients. Results of the Harvard Medical Practise Study 1. N Engl 7 Med 1991; 324:370-7.

5. Thomas EJ, Studdert DM, Burstin HR, et al. Incidence and types of adverse events and negligent care in Utah and Colorado. Med Care 2000;38:261-71.

6. Jagsi R, Kitch BT, Weinstein DF, et al. Residents report on adverse events and their causes. Arch Intern Med 2005;165: 2607-13.

7. Hobgood C, Hevia A, Tamayo-Sarver JH, et al. The influence of the causes and contexts of medical errors on EM residents' 
responses to their errors: an exploration. Acad Med 2005;80: 758-64.

8. Volpp KG, Grande D. Residents' suggestions for reducing errors in teaching hospitals. NEJM 2003;348:851-5.

9. Clark PA. What residents are not learning: observations in an NICU. Acad Med 2001;76:419-24.

10. Russell JC, Sklar D, Bagian J, et al. AAMC GRA/ORR Joint Committee on Patient Safety and Graduate Medican Education. Patient safety and graduate medical education. Washington (DC): Association of American Medical Colleges; 2003.

11. Committee on Optimizing Graduate Medical trainee (Resident) Hours and Work Schedules to Improve Patient Safety. Resident duty hours: enhancing sleep, supervision and safety. Washington (DC): National Academies Press; 2008.

12. Wu AW, Folkman S, McPhee SJ, et al. Do house officers learn from their mistakes? Qual Saf Health Care 2003;12:221-6; discussion 227-8.

13. Smith ML, Forster HP. Morally managing medical mistakes. Camb Q Healthc Ethics 2000;9:38-53.

14. Lawton R, Parker D. Barriers to incident reporting in a healthcare system. Qual Saf Health Care 2002;11:15-8.

15. Barach P, Small SD. Reporting and preventing medical mishaps: lessons from non-medical near miss reporting systems. BMJ 2000;320:759-63.

16. Friedman SM, Provan D, Moore S, et al. Errors, near misses and adverse events in the emergency department: What can patients tell us? CJEM 2008;10:421-7.

17. Evans SM, Berry JG, Smith BJ, et al. Attitudes and barriers to incident reporting: a collaborative hospital study. Qual Saf Health Care 2006;15:39-43.

18. Vincent C, Stanhope N, Crowley-Murphy M. Reasons for not reporting adverse incidents: an empirical study. 7 Eval Clin Pract 1999;5:13-21.

19. Friedman SM, Sommersall LA, Gardam M, et al. Suboptimal reporting of notifiable diseases in Canadian emergency departments: a survey of emergency physician knowledge, practices, and perceived barriers. Can Commun Dis Rep 2006; 32:187-98.

20. Hayes CW, Rhee A, Detsky ME, et al. Residents feel unprepared and unsupervised as leaders of cardiac arrest teams in teaching hospitals: a survey of internal medicine residents. Crit Care Med 2007;35:1668-72.

21. Frank JR, Danoff D. The CanMEDS initiative: implementing an outcomes-based framework of physician competencies. Med Teach 2007;29:642-7.

22. Cosby KS, Croskerry P. Profiles in patient safety: authority gradients in medical error. Acad Emerg Med 2004;11:1341-5.

23. Kohn LT, Corrigan JM, Donaldson MS. To err is buman: building a safer health system. Washington (DC): National Academy Press; 2000.

24. Dillman DA. Mail and internet surveys; the tailored design method. 2nd ed. New York (NY): John Wiley and Sons; 2000.
25. Hillson SD, Rich EC, Dowd B, et al. Call nights and patients care: effects on inpatients at one teaching hospital. 7 Gen Intern Med 1992;7:405-10.

26. Peberdy MA, Ornato JP, Larkin GL, et al. Survival from inhosital cardiac arrest during nights and weekends. JAMA 2008;299:785-92.

27. Al-Eissa M, Chu S, Lynch T, et al. Self-reported experience and competence in core procedures among Canadian pediatric EM fellowship trainees. CJEM 2008;10:533-8.

28. Singh H, Thomas EJ, Petersen LA, et al. Medical errors involving trainees: a study of closed malpractice claims from five insurers. Arch Intern Med 2007;167:2030-6.

29. Farnan JM, Johnson JK, Meltzer DO, et al. Resident uncertainty in clinical decision making and impact on patient care: a qualitative study. Qual Saf Health Care 2008;17:122-6.

30. Leape LL. Why should we report adverse incidents? I Eval Clin Pract 1998;5:1-4.

31. Cuschieri A. Nature of human error: implications for surgical practice. Ann Surg 2006;244:642-8.

32. Cosby KS, Croskerry P. Patient safety: a curriculum for teaching patient safety in EM. Academic EM 2003;10:69-78.

33. Thompson DA, Cowan J, Holzmueller C, et al. Planning and implementing a systems-based patient safety curriculum in medical education. Am J Med Qual 2008;23:271-8.

34. Gutierrez Cia I, Obon Azuara B, Aibar Remon C. A near-miss event. A new approach in the study of adverse events. Med Intensiva 2008;32:143-6.

35. Foster PN, Sidhu R, Gadhia DA, et al. Leveraging computerized sign-out to increase error reporting and addressing patient safety in graduate medical education. J Gen Intern Med 2008;23:481-4.

36. Rodriguez-Paz JM, Kennedy M, Salas E, et al. Beyond "see one, do one, teach one": toward a different training paradigm. Qual Saf Health Care 2009;18:63-8.

37. Canadian Patient Safety Institute (CPSI) in collaboration with The Royal College of Physicians and Surgeons of Canada. The safety competencies: enhancing patient safety across the health professions. Ottawa (ON): The Institute; 2008.

38. Swiggum S. Delegation and supervision of medical trainees. Ottawa (ON): Canadian Medical Protective Agency; 2008.

39. Barger LK, Ayas NT, Cade BE, et al. Impact of extendedduration shifts on medical errors, adverse events, and attentional failures. PLoS Med 2006; Dec;3(12):e487.

40. Barton A, Williams D, Beveridge M; Canadian Association of General Surgeons Committee for International Surgery. A survey of Canadian general surgery residents' interest in international surgery. Can 7 Surg 2008;51:125-9.

Correspondence to: Dr. Steven Marc Friedman, Department of Emergency Medicine, University Health Network, RFE G-S434, 200 Elizabeth St., Toronto ON M5G 2C4; steven.friedman@uhn.on.ca 